\title{
The investigation of GSTP1, APC and RASSF1 gene promoter hypermethylation in urine DNA of prostate-diseased patients
}

\author{
Haluskova $\mathrm{J}^{1}$, Lachvac $\mathrm{L}^{2}$, Nagy $\mathrm{V}^{2}$ \\ PJ Safarik University in Kosice, Faculty of Medicine, Department of Medical Biology, Kosice, Slovakia. \\ jana.haluskova12@gmail.com
}

\begin{abstract}
Objectives: Prostate cancer (PCa) represents one of the most complicated human tumors and, like many others malignancies, arises from progressive genetic and epigenetic alterations. Among all recognized epigenetic alterations, aberrant DNA methylation (hypo- and hypermethylation) is the most important and the best characterized change in PCa.

Background: We analyzed GSTP1, APC and RASSF1 gene promoter hypermethylation in urine DNA of ten previously non-treated prostate-diseased patients.

Methods: For the purpose, the quantitative real-time methylation specific PCR (MSP) with primers designed for amplification of methylated bisulfite-converted human DNA, followed by melting procedure, was currently optimized. Results: GSTP1 gene promoter hypermethylation was detected in 2 and 1 out of 5 patients with biopsy-confirmed PCa using the primers covering the $3^{\prime}$ and $5^{\prime} \mathrm{CpG}$ regions of the promoter, respectively. The APC gene promoter hypermethylation was found in neither of $\mathrm{PCa}$ or non-PCa patients and the RASSFI gene promoter hypermethylation was found in some non-PCa and not in all PCa patients.

Conclusions: Our results suggest that GSTP1 gene promoter hypermethylation can be detected in urine DNA of PCa patients with real-time MSP followed by melting. This enables evaluation of its potential as a useful biomarker in the diagnosis and prognosis of PCa (Tab. 1, Fig. 1, Ref. 9). Text in PDF www.elis.sk.

Key words: hypermethylation, prostate cancer, GSTP1, APC, RASSF1.
\end{abstract}

\section{Introduction}

Prostate cancer (PCa) represents one of the most complicated human tumors and, like many others malignancies, arises from progressive genetic and epigenetic alterations. Among all recognized epigenetic alterations, aberrant DNA methylation (hypoand hypermethylation) is the most important and the best characterized change in PCa. Hypermethylated genes in PCa include genes involved in detoxification of xenobiotics (e.g. glutathione S-transferase Pi (GSTP1)), DNA damage repair genes (e.g. DNA alkyl-repair gene $\mathrm{O}^{6}$-methylguanine methyltransferase (MGMT)), hormonal response genes (e.g. androgen receptor $(A R)$, estrogen receptor $(E R)$ ), cell-cycle control genes (e.g. CDKN2A), tumor suppressor genes (e.g. VHL, RB1, APC), apoptosis genes (e.g. death-associated protein kinase $(D A P K))$ and invasion and metas-

${ }^{1}$ PJ Safarik University in Kosice, Faculty of Medicine, Department of Medical Biology, Kosice, Slovakia, and ${ }^{2}$ PJ Safarik University in Kosice, Faculty of Medicine, Department of Urology, Kosice, Slovakia

Address for correspondence: J. Haluskova, RND, PhD, PJ Safarik University in Kosice, Faculty of Medicine, Department of Medical Biology, Trieda SNP 1, SK-040 11 Kosice, Slovakia.

Phone: +421.55 .2343390$

Acknowledgements: This work was supported by grant of VEGA - Scientific Grant Agency of the Ministry of Education of the Slovak Republic and of Slovak Academy of Sciences No: 1/0690/11 (70 \%) and by European funds project SEPO II (ITMS 26220120039) co-funded by the European Fund for Regional Development - 2009/2.1/02-SORO (30 \%). tasis genes (e.g. Cadherins, CD44, TIMPs). Aberrant DNA methylation might have a great potential as a diagnostic or prognostic marker for PCa and could be tested in tumor tissues and various body fluids (e.g. serum and urine) (1).

In order to detect methylated $\mathrm{CpG}$ sites, DNA samples are modified by sodium bisulfite. Sodium bisulfite deaminates cytosine and transforms it into uracil. Methylated cytosine, however, is not transformed by bisulfite treatment. Currently, methylationspecific PCR (MSP) and quantitative real-time MSP are two major techniques detecting methylation with the use of bisulfitemodified DNA (2).

In our preliminary study we analyzed GSTP1, APC and RASSF1 gene promoter hypermethylation in DNA from urine of previously non-treated prostate-diseased patients. For this purpose, we optimized quantitative real-time methylation-specific PCR (MSP) followed by melting procedure.

\section{Methods}

\section{Patients and urine collection}

The urine samples were collected at the Department of Urology, Faculty of Medicine, Pavol Jozef Šafárik University in Košice (Slovakia) according to (3). All patients gave informed consent for participation in the study. The PSA values, results of prostate biopsy and Gleason scores of patients are included in Table 1.

The DNA was isolated by NucleoSpin Tissue kit (MachereyNagel) according to manufacturer recommendations following 
Tab. 1. The patients' data and the results of GSTP1, APC and RASSF1 gene hypermethylation analysis.

\begin{tabular}{|c|c|c|c|c|c|c|c|c|c|}
\hline \multirow{2}{*}{$\begin{array}{l}\text { Patient } \\
\text { No: }\end{array}$} & \multirow{2}{*}{$\begin{array}{c}\text { PSA Value: } \\
\mathrm{ng} / \mathrm{ml}\end{array}$} & \multirow{2}{*}{$\begin{array}{l}\text { Result of } \\
\text { biopsy: }\end{array}$} & \multirow[t]{2}{*}{ Gleason: } & \multicolumn{6}{|c|}{ The presence of gene methylation detected with primers: } \\
\hline & & & & GSTP1a & GSTP1b & RASSF1a & RASSF1b & APCa & $\mathrm{APCb}$ \\
\hline 1 & - & - & - & - & - & - & - & - & - \\
\hline 2 & 22,0 & + & - & - & - & - & - & - & - \\
\hline 3 & 10,0 & - & - & - & - & + & - & - & - \\
\hline 4 & 9,9 & + & 6 & + & + & + & + & - & - \\
\hline 5 & - & - & - & - & - & + & + & - & - \\
\hline 6 & 12,0 & - & - & - & - & + & + & - & - \\
\hline 7 & 7,3 & + & 6 & + & - & + & + & - & - \\
\hline 8 & 7,8 & + & 6 & - & - & + & + & - & - \\
\hline 9 & 9,18 & + & 6 & - & - & - & - & - & - \\
\hline 10 & 51,7 & not available & - & - & - & + & + & - & - \\
\hline
\end{tabular}

the support protocol for purification of viral DNA from urine. The amount and purity of isolated DNA was evaluated by NanoDrop 2000 spectrophotometer (Thermo Scientific). Bisulfite modification of urine DNA was performed by means of MOD50-Imprint DNA Modification Kit (Sigma-Aldrich) according to manufacturer recommendations.

The quantitative real-time MSP amplification was performed in $20 \mu$ reaction volume containing $1 \mathrm{x}$ concentrated Maxima SYBR Green qPCR Master Mix (Thermo Scientific), $0.25 \mu \mathrm{M}$ GSTP1a, GSTP1b, APCa, APCb, RASSF1b and $0.5 \mu \mathrm{M}$ RASSF1a primers (Sigma-Aldrich), nuclease-free water (Thermo-Scientific) and around $10 \mathrm{ng}$ of bisulfite-converted template DNA.

The primer sequences were synthesized according to references as follows: GSTP1a - (4); GSTP1b - (5); APCa, RASSF1a - (6); APCb - (7) and RASSF1b - (8).

The fully methylated and unmethylated bisulfite-converted human control DNAs from EpiTect PCR Control DNA Set (Quiagen) were used as positive and negative controls, respectively. The other negative control with adding water instead of template DNA was included in each amplification reaction as well. The quantitative real-time MSP amplification was performed in 7500 Real Time PCR System (Applied Biosystems) and amplification conditions were as follows: I) $95{ }^{\circ} \mathrm{C}, 15$ minutes II) 45 cycles: $95{ }^{\circ} \mathrm{C}, 30$ seconds; $56{ }^{\circ} \mathrm{C}$ (GSTP1b), $60{ }^{\circ} \mathrm{C}$ (APCa, APCb, RASSFIAa and RASSFIAb) and $61{ }^{\circ} \mathrm{C}$ (GSTP1a) primers, 30 seconds; $72{ }^{\circ} \mathrm{C}, 1$ minute III) melting procedure: $95{ }^{\circ} \mathrm{C}, 15$ seconds; $60{ }^{\circ} \mathrm{C}, 1 \mathrm{~min}$ ute; $95^{\circ} \mathrm{C}, 30$ seconds; $60{ }^{\circ} \mathrm{C}, 15$ seconds.

\section{Results}

In the present study, we investigated GSTP1, APC and RASSF1 gene promoter hypermethylation in urine DNA of ten previously non-treated prostate-diseased patients. The quantitative real-time MSP followed by melting procedure was optimized for this purpose. In MSP we employed two pairs of primers for each gene which were designed to amplify the methylated bisulfite-converted human DNA in previous studies. The presence of promoter hypermethylation in the samples was evaluated by comparing their melting curves with that of commercially available fully methylated bisulfite-converted human DNA that served as a positive control.

The results of hypermethylation analysis are summarized in Table 1 . The GSTP1 gene hypermethylation was detected in 2 and 1 out of 5 patients with biopsy confirmed PCa using primers GSTP1a and GSTP1b, respectively. The melting curves of one $\mathrm{PCa}$ and one non-PCa patient obtained with primers GSTP1a and GSTP1b are shown in Figure 1A, B.

The APC gene hypermethylation was detected in neither of $\mathrm{PCa}$ or non-PCa patients and the RASSF1 gene hypermethylation was found in some non-PCa and was not detected in all PCa patients (Tab. 1).

\section{Discussion}

Payne et al (2009) (3) analyzed promoter hypermethylation of GSTP1, RASSF2, HIST1H4K and TFAP2E gene promoters in urine and plasma of patients referred for prostate biopsy and young asymptomatic males. They used HeavyMethyl qPCR which is realtime PCR method for detection of DNA methylation with oligonucleotide blockers specific to the unmethylated products. Their analysis significantly discriminated $\mathrm{PCa}$ from biopsy-negative patients and they revealed that the sensitivity of biomarkers was greater for urine than for plasma DNA. Daniunaite et al (2011) (9) analyzed RASSF1, RARB and GSTP1 promoter hypermethylation using quantitative real-time MSP with primers and hydrolysis probes which specifically amplified the bisulfite-converted fully methylated DNA derived from catheterized urine specimens of patients with biopsy-proven early or medium stage PCa. They revealed that especially RASSF 1 and $R A R B$ showed high sensitivity for the early non-invasive detection of PCa.

In our study, we employed the currently optimized quantitative real-time MSP followed by melting in order to analyze the GSTP1, APC and RASSF1 gene hypermethylation in DNA derived from urine of prostate-diseased patients. The melting procedure after real-time MSP was included in order to distinguish the possible non-specific amplification products from the specific ones.

The primer pairs employed for the GSTP1 hypermethylation analysis covered different $\mathrm{CpG}$ areas of the gene promoter: the GSTP1a primer pair from the study of Esteller et al (1998) spans the area of greatest $\mathrm{CpG}$ density immediately $5^{\prime}$ to the transcription start site. Thus, the GSTP1a primer pair covers the 3' $\mathrm{CpG}$ region of the promoter. The GSTP1b primer pair covering the $5^{\prime}$ $\mathrm{CpG}$ region of the gene promoter was chosen upon the results of Jain et al (2012) who demonstrated that the location of CpG sites is also important for specificity of GSTP1 gene promoter meth- 

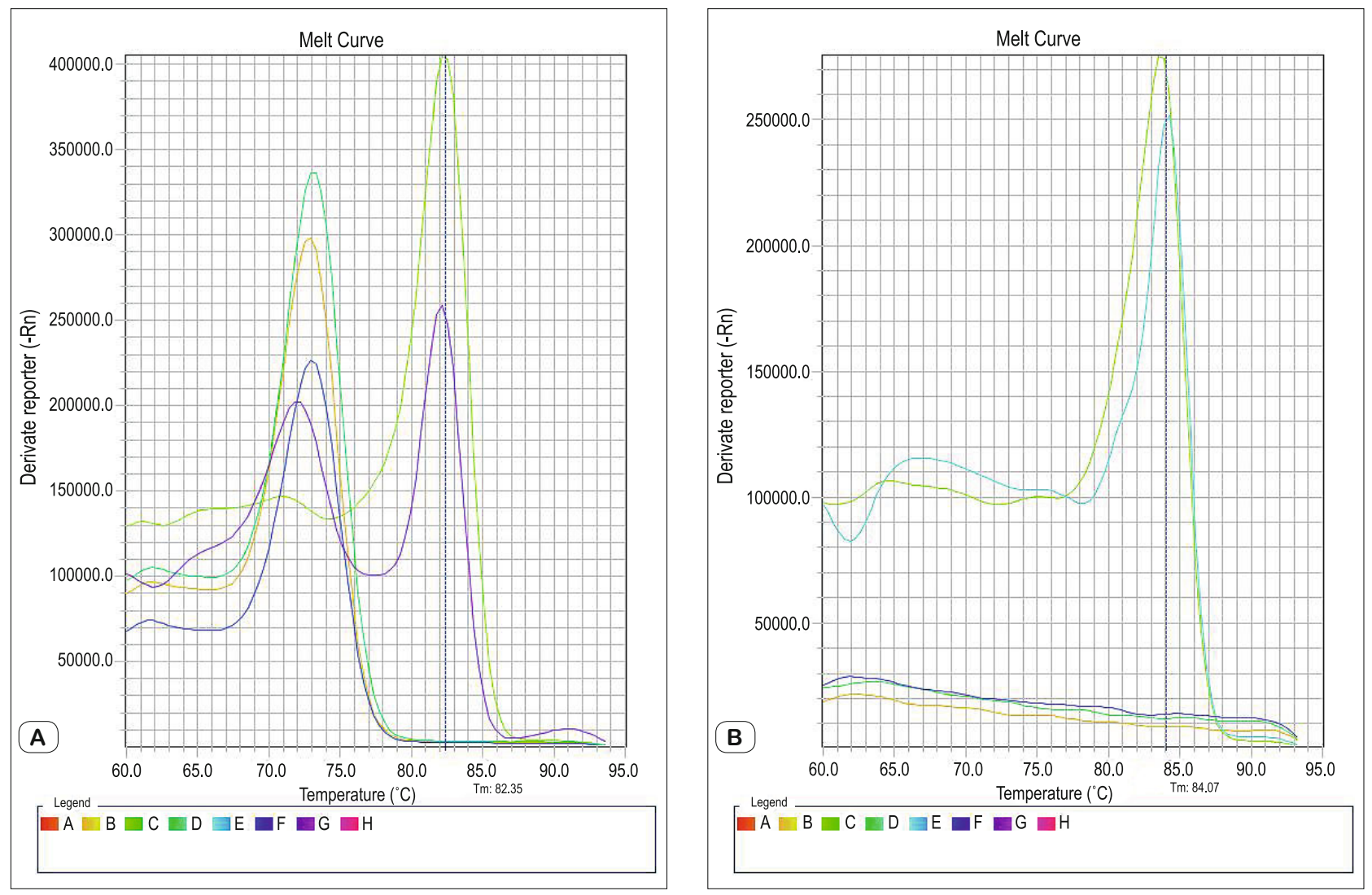

Fig. 1. The melting curves obtained after quantitative real-time MSP with urine DNA of prostate-diseased patients using: A) GSTP1a primer pair: B - negative control (water instead of template DNA), C - positive control (fully methylated bisulfite-converted human DNA as a template), D -- negative control (unmethylated bisulfite-converted human DNA as a template), F - non-PCa patient No 3, G - PCa patient No 7. B) GSTP1b primer pair: B - negative control (water instead of template DNA), C - positive control (fully methylated bisulfite-converted human DNA as a template), D - negative control (unmethylated bisulfite-converted human DNA as a template), E - PCa patient No 4, F - non-PCa patient No 5.

ylation analysis. The above mentioned authors revealed that the 5' CpG region of the position - $48 \mathrm{nt}$ from the GSTP1 gene transcription start site is selectively methylated in human hepatocellular carcinoma (HCC) whereas the $3^{\prime} \mathrm{CpG}$ region is methylated in all liver tissues they examined. In our study both GSTP1 primer pairs clearly distinguished $\mathrm{PCa}$ from non-PCa patients. Our results also indicate a possibility of different sensitivities of both GSTP1 primer pairs based on the fact that in contrast to the GSTP1a primers which detected hypermethylation in 2, the GSTP1b primers detected hypermethylation in only 1 out of 5 PCa patients.

The results of the APC gene hypermethylation analysis in our study may indicate that at the tumor stage with Gleason score 6 present in all PCa patients the gene promoter is not methylated.

In the case of RASSF1 gene promoter hypermethylation analysis, neither of the primer pairs distinguished $\mathrm{PCa}$ from non-PCa patients which may indicate they are non-specific. The results, however, are in compliance with the results of Rabiau et al (2009) who found the RASSF1 gene hypermethylation along with the histological samples from the Prostatic intraepithelial neoplasia (PIN), PeriTumor tissue (PTT) and Adenocarcinoma (ADC) also in non-malignant (NM) prostate biopsy samples. Thus, the RASSF1 gene promoter may be methylated in appropriate $\mathrm{CpG}$ regions in all prostate tissues with no distinction between histological degrees. On the other hand, Kang et al (2004) found no RASSF1 gene promoter hypermethylation in the samples from neither normal prostate or PIN. But we identified the gene hypermethylation with the primers from the study of Kang et al (2004) also in the non-PCa patients.

Considering the results of GSTP1 and APC gene promoter hypermethylation analysis, it is necessary to mention the non-specific amplification products which were present along with the specific ones in the melting curves of all samples. Because they were identified also in both negative controls, they might be the result of primers' self-amplification. The increase in annealing temperature from 61 to 64 and $66^{\circ} \mathrm{C}$ for the GSTP1a primers did not remove the formation of non-specific products. However, the non-specific products were clearly distinguishable from the specific ones and the melting curves could have been evaluated without any difficulty. It is interesting that the primers we tested in our study were employed also in previous studies in non-real-time MSP followed by electrophoresis. The non-specific products' formation, however, was not described by the authors. We suppose that the non-specific products formation in our study may be connected with the higher sensitivity of the quantitative real-time MSP technique. 


\section{9-82}

Finally, our results suggest that the quantitative real-time MSP followed by melting is useful for GSTP1 gene hypermethylation detection in urine DNA of PCa patients. However, the future study of many more patients will provide more relevant results concerning the effect of $\mathrm{CpG}$ site location within GSTP1 promoter on sensitivity of methylation analysis. Many more DNA samples even from patients with more progressive tumor stages have to be analyzed in the future in order to evaluate GSTP1 as well as APC gene promoter hypermethylation as useful biomarkers for diagnosis and prognosis of PCa. As for the RASSF1 gene, the specific primers for its gene promoter hypermethylation analysis which would clearly distinguish the $\mathrm{PCa}$ from non-PCa patients have to be found in the future.

\section{References}

1. Majumdar S, Buckles E, Estrada J, Koochekpour S. Aberrant DNA methylation and prostate cancer. Curr Genomics 2011; 12: 486-505.

2. Park JY. Promoter hypermethylation in prostate cancer. Cancer Control 2010; 17: 245-255.

3. Payne SR, Serth J, Schostak M, Kamradt J, Strauss J, Thelen P, Model F, Day JK, Liebenberg V, Morotti A, Yamamura S, Lograsso J, Sledziewski A, Semjonow A. DNA methylation biomarkers of prostate cancer: confirmation of candidates and evidence urine is the most sensitive body fluid for non-invasive detection. Prostate 2009; 69: 1257-1269.

4. Esteller M, Corn PG, Urena JM, Gabrielson E, Baylin SB, Herman JG. Inactivation of glutathione S-transferase P1 gene by promoter hypermethylation in human neoplasia. Cancer Res 1998; 58: 4515-4518.

5. Jain S, Chen S, Chang K-C, Lin Y-J, Hu C-T, Boltbaatar B, Hamilton JP, Lin SY, Chang T-T, Chen S-H, Song W, Meltzer SJ, Block TM, Su Y-H. Impact of the location of CpG methylation within the GSTP1 gene on its specificity as a DNA marker for hepatocellular carcinoma. PLoS ONE 2012; 7: e35789.

6. Kang GH, Lee S, Lee HJ, Hwang KS. Aberrant CpG island hypermethylation of multiple genes in prostate cancer and prostatic intraepithelial neoplasia. J Pathol 2004; 202: 233-240.

7. Rigi-Ladiz MA, Kordi-Tamandani DM, Torkamanzehi A. Analysis of methylation and expression profiles of APC and ATM genes in patients with oral squamous cell carcinoma. Clin Epi. 2011; 3: 6 .

8. Rabiau N, Thiam MO, Satih S, Guy L, Kemeny J-L, Boiteux J-P, Fontana L, Bignon Y-J, Bernard-Gallon D. Methylation analysis of BRCA1, RASSF1, GSTP1 and EPHB2 promoters in prostate biopsies according to different degrees of malignancy. In vivo 2009; 23: 387-392.

9. Daniunaite K, Berezniakovas A, Jankevicius F, Laurinavicius A, Lazutka JR, Jarmalaite S. Frequent methylation of RASSF1 and RARB in urine sediments from patients with early stage prostate cancer. Medicina (Kaunas) 2011; 47: 147-153. 